Yurisa Irawan, R. Widya Setiabudi Sumadinata, Windy Dermawan | Fragmentasi

Pemberontak Dan Durasi Perang Sipil: Thailand Selatan Pasca

Dimediasi Organisasi Kerjasama Islam

Article

\title{
Fragmentasi Pemberontak Dan Durasi Perang Sipil: Thailand Selatan Pasca Dimediasi Organisasi Kerjasama Islam
}

Yurisa Irawan ${ }^{1}$, R. Widya Setiabudi Sumadinata ${ }^{2}$, Windy Dermawan ${ }^{3}$

${ }^{1}$ Hubungan Internasional, Universitas Padjadjaran, Jawa Barat, Indonesia

${ }^{2}$ Hubungan Internasional, Universitas Padjadjaran, Jawa Barat, Indonesia

${ }^{3}$ Hubungan Internasional, Universitas Padjadjaran, Jawa barat, Indonesia

\section{SUBMISSION TRACK}

$\begin{array}{ll}\text { Recieved } & : \text { 22 May } 2019 \\ \text { Final Revision } & : \text { 25 September } 2019 \\ \text { Available Online } & : \text { 30 November } 2019\end{array}$

KEYWORD

Southern Thailand Conflict, Civil War Duration, Organization of Islamic Conference (OIC),

Bargaining Theory

KATA KUNCI

Konflik Thailand Selatan, Durasi Perang Sipil, Organisasi Kerjasama Islam, Teori Perundingan

\section{CORRESSPONDENCE}

E-mail : yurisa.irawan2206@gmail.com

\section{A B S T R A C T}

Rebel fragmentation is considered significant to determine civil conflict duration. It prolongs achievement of agreement though the conflict has been mediated. This article qualitatively studies that issue through deploying the ongoing Southern Thailand conflict as case study to understand how the fragmentation could ignore third party-mediated peaceprocess amid civil conflict. Regardless the Organization of the Islamic Conference (OIC) involvement since 2005, the violent conflict continues. This study utilizes the bargaining theory to frame and interpret related qualitative data as research method. It shows disintegration among Pattani rebel groups, which can be noticed through diversification of aims, methods, and background, has contributed to civil conflict prolongation. It also finds that the rebel fragmentation diversifies in three ways: rebel identity connection, mediation capability, and the absence of umbrella groups for Malay Muslim society in the south.

\section{A B S T R A K}

Fragmentasi pemberontak dianggap signifikan menentukan durasi konflik sipil dengan memperlama tercapainya kesepakatan meskipun konflik telah dimediasi. Tulisan ini mempelajari secara kualitatif persoalan tersebut dengan menggunakan konflik Thailand Selatan yang sedang berlangsung sebagai studi kasus untuk memahami bagaimana di tengah konflik sipil fragmentasi mampu mengabaikan proses perdamaian yang dimediasi pihak ketiga. Konflik kekerasan berlanjut meskipun Organisasi Konferensi Islam (OKI) telah terlibat. Penelitian ini memanfaatkan teori perundingan untuk membingkai dan menginterpretasikan data kualitatif yang relevan sebagai metode penelitian. Hasilnya, tampak bahwa perpecahan di tengah kelompok pemberontak Pattani, yang terlihat lewat beragamnya tujuan, metode, dan latar belakang, telah berkontribusi terhadap pelanggengan konflik sipil. Penelitian ini juga menemukan bahwa fragmentasi tersebut terpecah ke dalam tiga aspek: koneksi identitas pemberontak, kapabilitas mediasi, dan ketiadaan organisasi payung bagi masyarakat Melayu Muslim. 


\section{Pendahuluan}

Sejak berakhirnya Perang Dunia Kedua, intensitas konflik intra negara atau perang sipil tidak hanya lebih tinggi dibandingkan dengan konflik antar negara, tetapi juga sulit untuk diselesaikan atau berlangsung dalam durasi yang lama. ${ }^{2} \mathrm{Hal}$ inilah yang mendorong bidang studi hubungan internasional menggiatkan penelitian mengenai konflik internal negara. $^{3}$ Beberapa perang sipil dicirikan oleh adanya perlawanan bersenjata maupun pemberontakan yang dilakukan oleh sekelompok orang yang dianggap mewakili identitas tertentu - biasanya minoritas yang bertentangan dengan pemerintah pusat. Salah satu contoh yang mencolok, tetapi sering diabaikan, adalah konflik Thailand Selatan yang berlangsung antara pemerintah Thailand dengan kelompok pemberontak yang dianggap mewakili identitas masyarakat minoritas etnis Muslim Melayu, yang dominan di beberapa provinsi di selatan negara tersebut. Akar konflik dapat ditarik sejak abad kesembilan belas, tetapi kekerasan yang tengah berlangsung terjadi sejak 2004. Per tahun 2017, International Crisis Group mencatat, paling tidak 7000 jiwa telah tewas sejak kekerasan terakhir terjadi. $^{4}$

Sejauh ini, beberapa aspek telah dapat dikenali dari konflik Thailand Selatan. Anders Engvall dan Magnus Anderson, misalnya, telah menunjukan

\footnotetext{
${ }^{1}$ Magnus Öberg and Kaare Strøm, Resources, Governance, and Civil Conflict (Oxon: Routledge, 2008), 4.

${ }^{2}$ Barbara F. Walter, "Civil Wars, Conflict Resolution, and Bargaining Theory," in Handbook of International Relations, 2nd ed. (London: Sage Publication, 2013), 656.

${ }^{3}$ Christopher Blattman and Miguel Edward, "Civil War," Journal of Economic Literature 48, no. 2 (2009): 3-57.

${ }^{4}$ International Crisis Group, Jihadism in Southern Thailand: A Phantom Menace (Brussels: International Crisis Group, 2017), ii.
}

bahwa konflik berakar pada persoalan kultural - linguistik khususnya - dan ekonomi. $^{5}$ Kemudian Diana Sarosi dan Janjira Sombatponsiri juga telah mengkaji bagaimana kebijakan nasional pemerintah turut memperparah situasi di selatan. Situasi memburuk tidak hanya dikarenakan kudeta militer di tahun 2006 tetapi juga adanya kebijakan untuk melonggarkan kepemilikan senjata api kepada penduduk sipil. $^{6}$ Di samping itu, Neil J. Melvin juga telah membahas perpecahan di dalam struktur pemberontak serta penguatan pengaruh militer Thailand yang diyakini telah menjadi kesulitan utama proses perdamaian. ${ }^{7}$ Namun, hambatan terhadap upaya penyelesaian tersebut menarik untuk diuji kembali terlebih ketika itu dilihat sebagai konflik yang tidak kunjung bisa diselesaikan kendati telah melibatkan pihak ketiga sebagai mediator.

Dengan menjadikan konflik Thailand Selatan sebagai studi kasus, penelitian ini bermaksud menguji teori perundingan (bargaining theory) yang berupaya menjelaskan lamanya durasi perang sipil. Penelitian ini difokuskan kepada pertanyaan bagaimana fragmentasi kelompok pemberontak yang mewakili kelompok Melayu Muslim di Thailand Selatan berkontribusi dalam memperlama durasi konflik tersebut. Hal itu signifikan untuk dikaji mengingat sebetulnya telah ada upaya mediasi yang dilakukan oleh Organisasi Konferensi Islam (OKI) sejak tahun 2005 agar tercapai perundingan

\footnotetext{
5 Anders Engvall and Magnus Anderson, The Dynamics of Conflict in Southern Thailand, 2014, 181-186.

${ }^{6}$ Diana Sarosi and Janjira Sombatpoonsiri, “Arming Civilians for Self-Defense : The Impact of Firearm Proliferation on the Conflict Dynamics in Southern Thailand," Global Change, Peace \& Security 23, no. 3 (2011): 387-403.

${ }^{7}$ Neil J Melvin, 'Conflict in Southern Thailand: Islamism, Violence, and the State in the Patani Insurgency', SIPRI Policy Paper, no. 20 (2007): 38.
} 
Yurisa Irawan, R. Widya Setiabudi Sumadinata, Windy Dermawan | Fragmentasi

Pemberontak Dan Durasi Perang Sipil: Thailand Selatan Pasca

Dimediasi Organisasi Kerjasama Islam

antara pemerintah Thailand dengan pemberontak, tetapi kesepakatan di antara keduanya belum tercapai. Padahal jika dilihat dari apa yang telah dilakukan, OKI memiliki kapabilitas sebagai aktor resolusi konflik, terutama "pencegah konflik kekerasan" (preventing violent conflict) berdasarkan model resolusi konflik yang kredibel seperti "model Hourglass". Keberhasilan OKI dalam mencegah konflik di Thailand agar tidak berlanjut dari fase kekerasan ke peperangan terbuka, ${ }^{8}$ tidak disertai oleh penurunan tahapan konflik ke arah yang lebih damai. Tanpa bermaksud mengabaikan evaluasi terhadap kinerja OKI, maupun hambatan yang mungkin muncul dari pemerintah Thailand sendiri, fokus penelitian ini diarahkan pada kondisi objektif pihak pemberontak, yang boleh jadi perpecahan di antara mereka membuat kesepakatan sulit dicapai.

\section{Metode Penelitian}

Penelitian ini dirancang dalam bentuk kualitatif dengan studi kasus. Konflik Thailand selatan diperlakukan sebagai contoh untuk membuktikan dan mendalami bagaimana keterhubungan antara fragmentasi pemberontak dengan durasi perang sipil. Hubungan ini didasarakan kepada teori perundingan yang dikembangkan oleh Barbara F. Walter. Adapun data yang digunakan adalah berupa teks baik dalam bentuk dokumen, buku, maupun jurnal. Analisis terhadap teks dilakukan untuk menginterpretasikan kondisi di Thailand Selatan sehingga diperoleh gambaran yang mengaitkan antara teori dengan praksis.

\footnotetext{
${ }^{8}$ Yurisa Irawan, "Strategi Resolusi Konflik Organisasi Kerjasama Islam (OKI) Dalam Konflik Thailand Selatan" (Universitas Andalas, 2016).
}

\section{Teori Perundingan}

Untuk menjelaskan mengapa konflik kekerasan masih terus terjadi di Thailand Selatan, bahkan setelah dimediasi oleh OKI sekalipun, penelitian ini membutuhkan teori perundingan yang dikembangkan oleh Barbara F. Walter. Teori tersebut dirancang untuk melihat mengapa perang sipil sulit dihentikan. Teori ini, alih-alih menjelaskan bagaimana perang sipil terjadi, justru ditekankan kepada persoalan mengapa hal itu begitu sulit dihentikan. Kombatan seolah enggan bernegosiasi dan menerapkan penyelesaian yang kompromis. ${ }^{9}$ Dengan logika yang sama, penelitian ini tidak mencoba mengajukan pertanyaan mengapa konflik kekerasan berlatar etnis terjadi di Thailand Selatan, melainkan mengapa kekerasan tersebut seolah tidak berhenti sejak tahun 2004.

Terkait hubungan antara dinamika pemberontakan dengan luaran konflik, Walter menekankan kepada tiga hal. Fokus pertama adalah untuk memahami stagnansi konflik atau perang sipil dengan melihat kepada keluhan dan kemurkaan yang memotivasi suatu kelompok untuk menentang negara di mana mereka berada. Kedua adalah seberapa jauh kesempatan yang tersedia bagi suatu kelompok untuk menggerakkan dukungan dan membangun pergerakan. Namun, menurut Walter, keduanya tidak cukupuntuk menjelaskan mengapa perang sipil terjadi secara terus menerus dan mengapa para kombatan menolak penyelesaian. Untuk menutup kerumpangan tersebut, Walter berpandangan bahwaaspek ketiga, proses perundinganlah, baik sebelum, sedang, maupun sesudah perang terjadi yang menentukan mengapa perang terus berlangsung. Dengan kata lain, proses di dalam perundingan menentukan

\footnotetext{
${ }^{9}$ Walter, "Civil Wars, Conflict Resolution, and Bargaining Theory," 656.
} 
Yurisa Irawan, R. Widya Setiabudi Sumadinata, Windy Dermawan | Fragmentasi

Pemberontak Dan Durasi Perang Sipil: Thailand Selatan Pasca

Dimediasi Organisasi Kerjasama Islam

kecenderungan kombatan untuk memilih apakah mereka akan menggunakan kekerasan atau duduk satu meja yang dimediasikan. ${ }^{10}$ Apabila gagasan Walter diterima pada konflik Thailand Selatan, maka secara hipotetis, yang menjadi masalah adalah ada hambatan perundingan yang boleh jadi datang dari pihak pemberontak.

\section{Hasil dan Diskusi}

Beberapa aspek telah dieksplor oleh studi terdahulu mengenai konflik Thailand Selatan, terutama yang melibatkan OKI sebagai aktor resolusi konflik, tetapi belum satupun yang mencoba melihat durasi konflik tersebut dalam kerangka kelancaran atau keterhambatan perundingan yang dilakukan oleh mediator sebagai sesuatu yang dipengaruhi oleh perpecahan di tubuh pihak yang berkonflik sendiri, atau pada pemberontak lebih tepatnya. Literatur yang telah ada dapat dikelompokan menjadi tiga hal, berdasarkan kesamaan pembahasan, yaitu: yang fokus pada akar konflik atau menjelaskan mengapa konflik terjadi; melihat upaya penyelesaian konflik oleh mediator seperti OKI; dan kendala yang ditemukan dalam proses penyelesaian konflik di Thailand Selatan. Penelitian ini sesuai dengan kategori ketiga dengan sumbangsih memberi penekanan pada fragmentasi pemberontak.

Pada umumnya, studi tentang konflik di wilayah Pattani dan sekitarnya dijelaskan dengan persoalan linguistik dan ekonomi sebagai akar masalah utama. Dalam proses pembentukan bangsa, Pemerintah Thailand telah menetapkan atau memaksakan penggunaan bahasa Thai bagi penduduk Melayu di selatan tanpa memberikan mereka kesempatan untuk mempertahankan dan mengembangkan bahasa daerahnya sendiri. Kondisi itu diperparah oleh adanya ketimpangan antara

${ }^{10}$ Ibid., 657. daerah selatan yang relatif miskin dengan daerah lain di Thailand. ${ }^{11}$ Beberapa penulis lain juga menilai, bahwa selain faktor budaya dan ekonomi tersebut, konflik juga disebabkan oleh kondisi politik negara Thailand yang tidak stabil karena sering mengalami kudeta militer. ${ }^{12}$ Persoalan di bidang sosial-budaya, ekonomi, dan politik ini dapat dikatakan telah melatarbelakangi konflik jauh sebelum aksi kekerasan terakhir terjadi pada 2004, yaitu sejak integrasi bekas kawasan kerajaan Melayu Pattani ke kerajaan Siam.

Beberapa pandangan mengarahkan fokus pada keterlibatan pihak ketiga atau mediator sejak konflik pecah tahun 2004. Salah satu yang terlibat dalam proses bina damai ini adalah OKI. Kendati jarang dibahas, secara umum keikutsertaan OKI sebagai aktor resolusi konflik di luar Thailand bukanlah hal yang baru. Perannya sebagaimediator telah diakui oleh masyarakat internasional dengan mekanisme operasionalnya sendiri. ${ }^{13}$ Keterlibatan dalam resolusi konflik organsisasi tersebut kentara tidak hanya di dunia Islam, ${ }^{14}$ tetapi juga di kawasan Asia Tenggara yang tidak sepenuhnya menggambarkan masyarakat Islam. ${ }^{15}$ Berbekal pengalaman demikianlah,

\footnotetext{
${ }^{11}$ Anders Engvall and Magnus Anderson, The

Dynamics of Conflict in Southern Thailand, 2014, 181-186.

${ }^{12}$ Diana Sarosi and Janjira Sombatpoonsiri, “Arming Civilians for Self-Defense : The Impact of Firearm Proliferation on the Conflict Dynamics in Southern Thailand," Global Change, Peace \& Security 23, no. 3 (2011): 387-403.

${ }^{13}$ Victor Luis Gutierrez Castillo, The Organization of Islamic Cooperation in Contemporary

International Society, 2014, 19.

${ }^{14}$ Ibrahim Sharqieh, "Can the Organization of Islamic Cooperation (OIC) Resolve Conflict?," Peace and Conflict Studies 19, no. 2 (2012): 163.

${ }^{15}$ Kathrine Rupprecht, "Separatist Conflicts in the ASEAN Region: Comparing Southern Thailand and Mindanao," Austrian Journal of South-East Asian Studies 1, no. 7 (2014): 21-40.
} 
Yurisa Irawan, R. Widya Setiabudi Sumadinata, Windy Dermawan | Fragmentasi

Pemberontak Dan Durasi Perang Sipil: Thailand Selatan Pasca

Dimediasi Organisasi Kerjasama Islam

beberapa pakar menegaskan bahwa peran OKI dalam konflik Thailand Selatan tidak bisa diabaikan. ${ }^{16}$

Berhubung aksi OKI sebagai mediator mendapat tantangan tersendiri, beberapa literatur fokus untuk menjelaskan hal tersebut sebagai bagian dari kendala yang ditemui dalam proses perundingan konflik Thailand Selatan. Salah satu kendala itu, menurut Waesahmae, muncul ketika OKI dan Thailand memiliki perbedaan pandangan dalam upaya penyelesaian. Saran OKI untuk mempertemukan pemerintah dengan pemberontak di dalam satu meja tidak begitu populer. ${ }^{17} \mathrm{Hal}$ ini pula yang menurut beberapa pandangan OKI tertinggal dari PBB dalam upaya resolusi konflik, ${ }^{18}$ walaupun dalam konteks Thailand justru PBB yang tidak memiliki kapabilitas untuk mengakses daerah konflik tersebut.Di tambah lagi dengan mengingat OKI cukup berhasil dalam konflik di negara lain seperti di Filipina, ${ }^{19}$ maka klaim bahwa OKI tidak cukup memiliki kapabilitas dalam upaya resolusi konflik belum tentu tepat. Barangkali ada faktor-faktor lain yang terjadi dalam proses perundingan yang selama ini belum terbaca oleh literatur tersebut yang membuat transformasi konflik Thailand Selatan terhambat.

\section{Diskusi}

Sebelum masuk kepada fragmentasi pemberontak dan hambatan perundingan,

\footnotetext{
${ }^{16}$ Imtiyaz Yusuf, "The Southern Thailand Conflictandthe Muslim World," Journal of Muslim Minority Affairs 2, no. 27 (2007): 319-339.

${ }^{17}$ Paoyee Waesahme, "The Organization of the Islamic Cooperation and the Conflict in Southern Thailand" (Victoria University of Wellington, 2012), 48-51.

${ }^{18}$ Shahih Ahmad Hashmat, The OIC Potential, Capabilities and Constraints for International Conflict Resolution (Islamabad, 2014), 117-118.

${ }^{19}$ Sharqieh, "Can the Organization of Islamic Cooperation (OIC) Resolve Conflict?," 163.
}

ada tiga hal yang perlu mendapat perhatian. Pertama, konflik Thailand Selatan, terlepas dari beragam aktor yang terlibat di dalamnya, adalah konflik yang dilandasi oleh perbedaan identitas yang signifikan. Bagaimana pihak yang terlibat, termasuk mediator dalam memainkan politik identitas ini akan menentukan dinamika konflik. Kedua, konflik tersebut ditempatkan pada persoalan yang sebetulnya telah memperoleh perhatian dari pihak ketiga yang memahami benturan identitas tersebut, yaitu OKI. Hanya saja organisasi tersebut belum mampu untuk mendudukan pihak terkait guna membuka jalan kepada rekonsiliasi identitas. Ketiga, peristiwa terobservasi bagaimana konflik tersebut berlangsung tetap penting.

\section{Identitas Melayu sebagai Poros Utama Konflik}

Identitas sebagai Melayu Muslim barangkali adalah kunci yang menghubungkan antara perang sipil di selatan, dinamika pemberontakan, dan ukuran pencapaian mediator seperti OKI. Kendati Thailand tidak teregistrasi sebagai negara anggota OKI, organisasi ini telah melibatkan diri dalam proses perundingan justru karena disebabkan memiliki mandat untuk melakukan perlindungan terhadap minoritas Muslim termasuk di negara nonanggota. ${ }^{20}$ Data dari Pew Research Center menunjukan $5.5 \%$ penduduk Thailand adalah Muslim. Dapat dikenali bahwa kendatipun lembaga tersebut juga merujuk Muslim beretnis Thai dalam komposisi tersebut, etnis Melayu Muslim adalah yang dominan. Jumlah itu hampir setara dengan populasi Muslim minoritas di Filipina dan Myanmar. Namun, diproyeksikan, akan ada peningkatan penduduk Muslim di Thailand

\footnotetext{
${ }^{20}$ Waesahme, "The Organization of the Islamic Cooperation and the Conflict in Southern Thailand," 20.
} 
Yurisa Irawan, R. Widya Setiabudi Sumadinata, Windy Dermawan | Fragmentasi

Pemberontak Dan Durasi Perang Sipil: Thailand Selatan Pasca

Dimediasi Organisasi Kerjasama Islam

sebesar $8.3 \%$ pada tahun 2050, mengungguli dua negara lainnya. ${ }^{21}$

Konflik yang terjadi antara

Pemerintah Thailand dan kelompok

pemberontak Thailand Selatan

sesungguhnya sudah berlangsung cukup

lama. Akar historis konflik ini bermula saat terbentuknya perjanjian Anglo-Siam pada tahun 1909. Dalam perjanjian tersebut, wilayah selatan Thailand (Kerajaan Muslim Melayu atau disebut juga dengan Kesultanan Patani) dipaksa masuk kedalam wilayah Thailand (dulu bernama Siam). Dengan latar belakang budaya dan agama yang berbeda, Thailand Selatan merasa terasingkan dengan kebijakan-kebijakan pemerintah Thailand saat itu. Pemerintah Thailand menjadikan bahasa Thailand sebagai 'a fundamental ingredient of Thainess' dan 'sumber kehidupan dan tradisi nasional. Bahkan secara terang-terangan mereka mengungkapkan bahwa eksistensi bangsa Thai bergantung dengan bahasa Thai. ${ }^{22}$ Upaya pembentukan nasionalisme yang dilakukan oleh pemerintah Thailand ini dianggap merugikan etnis Melayu Muslim sehingga muncul berbagai kelompok pemberontak guna melawan pemerintah.

\section{Fase Konflik dan Masuknya Pihak Ketiga}

Persoalan yang terjadi di Thailand Selatan dapat dikategorikan baik sebagai konflik sipil, perang sipil, maupun konflik kekerasan. Istilah pertama dan kedua dapat dipertukarkan selagi menyangkut konflik bersenjata paling tidak antara dua pihak: negara dengan satu atau lebih kelompok pemberontak di dalam negara tersebut. ${ }^{23}$

\footnotetext{
${ }^{21}$ Pew Templation, "Global Religious Futures," accessed November 4, 2018,

http://www.globalreligiousfutures.org/countries.

${ }^{22}$ Chris Baker and Pasut Phongpaichi, A History of

Thailand (Cambridge: Cambridge University Press, 2014), 112.

${ }^{23}$ Öberg and Strøm, Resources, Governance, and Civil Conflict, 3.
}

Namun, perang sipil terkadang tidak selalu hadir dalam pertempuran terbuka, tetapi dapat berupa rangkaian aksi kekerasan dengan korban yang tidak sedikit antara pemerintah dan pemberontak yang terus berlanjut. Ramsbotham, Woodhouse, dan Miall memosisikan konflik Thailand Selatan berapada pada fase konflik kekerasaan dalam model resolusi konflik mereka, Hourglass. Mereka menghimpun data konflik sipil yang masih berlangsung pada 2008-2009 dalam laman systemicpeace.org danbelum menempatkan konflik Thailand Selatan pada tahap perang. ${ }^{24}$ Belakangan, situs tersebut masih mengategorikan konflik Thailand Selatan pada tahap kekerasan (violence). ${ }^{25}$ Kolonel Patcharawat Thnaprarnsing dari Royal Thai Army juga mengidentifikasinya berada pada tahap kekerasan. ${ }^{26}$

Dalam konflik Thailand Selatan, OKI dapat dikatakan telah berhasil melakukan beberapa bentuk pencegahan konflik kekerasan. Indikator hal tersebut dapat dilihat dari model Hourglass bahwa pihak ketiga pencegah konflik kekerasan memiliki tiga target utama: 1) mencegah perang, 2) mencegah kekerasan yang lebih serius, dan 3) mentransformasi konflik ke tahap de-eskalasi, atau mendekati perdamaian. $^{27}$

\footnotetext{
${ }^{24}$ Oliver Ramsbotham, Tom Woodhouse, and Hugh Miall, Contemporary Conflict Resolution: The Prevention, Management and Transformation of Deadly Conflicts (Cambridge: Polity Press, 2011), 68.

${ }^{25}$ Center for Systemic Peace, "Major Episodes of Political Violence 1946-2014," accessed November 16,2018 ,

http://www.systemicpeace.org/warlist/warlist.htm\#.

${ }^{26}$ Patcharawat Thnapramsing, "Solving the Conflict in Southern Thailand," Strategy Research Project (2009): 1 .

${ }^{27}$ Ramsbotham, Woodhouse, and Miall, Contemporary Conflict Resolution: The Prevention, Management and Transformation of Deadly Conflicts, 123-144.
} 
Yurisa Irawan, R. Widya Setiabudi Sumadinata, Windy Dermawan | Fragmentasi

Pemberontak Dan Durasi Perang Sipil: Thailand Selatan Pasca

Dimediasi Organisasi Kerjasama Islam

OKI mampu memenuhi dua target pertama, tetapi belum tampak berhasil dalam target ketiga.Organisasi ini bergerak cepat sejak tahun 2005 dengan terlebih dahulu menanggapi situasi di sana langsung oleh Sekretaris Jenderal mereka, Ekmeleddin Ihsanoglu lewat rilisan pers.Ia mengungkapkan rasa prihatin atas kejadian yang menimpa masyarakat Muslim dan mengecam keras pemerintah Thailand atas tindakan mereka. OKI menyerukan agar konflik Thailand Selatan dilaksanakan upaya negosiasi dan dialog damai untuk menyelesaikan semua permasalahan yang dihadapi umat Islam di Thailand. OKI juga menyerukan kepada pemerintah Thailand agar memperlakukan masyarakat Muslim di Thailand Selatan sejajar dengan warga negara lainnya. ${ }^{28}$ Hingga sekarang, OKI tetap aktif dalam upaya resolusi.OKI telah melakukan pendekatan komunikatif dengan mengeluarkan rilisan pers dan membuka saluran dialog dengan pemerintah Thailand dan pemberontak, masing-masing sejak 2010 dan 2005. Namun, seperti yang diketahui, berbagai proses perundingan dan resolusi yang diupayakan tidak berjalan seperti yang diharapkan. Kesepakatan antara pemerintah Thailand dengan pihak pemberontak belum tercapai. Dialog yang dilakukan OKI bersifat terpisah dan belum mampu mempertemukan pemerintah Thailand duduk satu meja dengan pihak pemberontak. Dalam konteks demikian, proses perundingan tampaknya mengalami kemandekan.

\section{Dinamika Konflik dan Kapabilitas OKI}

Ketegangan yang terjadi di wilayah Thailand Selatan terus mengalami pasang surut sejak bergabungnya Pattani dengan Thailand lewat Traktat Anglo-Siam tahun 1902. Namun, konflik saat ini adalah

\footnotetext{
${ }^{28}$ Yusuf, "The Southern Thailand Conflictandthe Muslim World," 20.
}

keberlanjutan dari peristiwa kekerasan tahun 2004. Beberapa insiden kekerasan, seperti penyerangan gudang senjata militer Thailand di Narathiwat oleh sekelompok pemberontak, menandai hal tersebut. Ratusan senjata dirampas dan belasan sekolah dibakar. Menanggapi hal tersebut, pemerintah menetapkan wilayah selatan sebagai darurat militer serta mengirim pasukan tambahan sebanyak 10.000 orang yang bergabung dengan 20.000 pasukan yang sebelumnya telah ditempatkan di sana. 29

Kondisi darurat militer diperparah oleh aksi kekerasan lanjutan di sepanjang tahun 2004. Dua peristiwa penting setidaknya mendapat banyak sorotan. Pertama, serangan terhadap Masjid Krue Se di Pattani pada 28 April oleh polisi dan tentara Thailand. Kejadian bermula ketika sekelompok militan muda yang melakukan penyerangan terhadap pos keamanan di Pattani, Songkhla, dan Yala, diduga bersembunyi di dalam masjid. Aparat keamanan pun mengejar mereka dan mengepung masjid sebelum melepaskan tembakan. Tiga puluh dua orang dari pihak pemberontak dan satu orang warga sipil tewas dalam serangan tersebut. ${ }^{30}$ Kedua, insiden di Tak Bai, Naratthiwat, pada 25 Oktober. Peristiwa itu bermula ketika ribuan demonstran berkumpul di depan pos polisi di Tak Bai dan menuntut pihak keamanan agar membebaskan 6 warga sipil yang dituduh sebagai pemasok senjata bagi

\footnotetext{
${ }^{29}$ Ian Storey, "Ethnic Separatism in Southern Thailand : Kingdom Fraying at the Edge?," AsiaPacific Center for Security Studies 35, no. 1 (2007): 5.

${ }^{30}$ Joseph Chinyong Liow, Muslim Resistance in Southern Thailand and Southern Philippines: Religion, Ideology and Politics (Washington D.C: The East-West Center Washington, 2006); Gede Richard Pramudita, Idin Fasisaka, and Putu Titah Kawatri, "Tindakan Pemerintah Thailand Dalam Merespons Gerakan Etnonasionalisme Di Thailand Selatan Tahun 2004-2006" (Universitas Udayana, 2015), 8.
} 
kelompok separatis. Untuk membubarkan demonstran, pihak keamanan melepaskan tembakan gas air mata dan senjata api serta melakukan pemukulan. Tujuh orang tewas di tempat ketika itu dan 1.298 demonstran ditangkap dan dibawa ke pos keamanan di Pattani menggunakan truk. Dalam perjalanan, 78 orang tewas karena kekurangan oksigen di dalam truk. Ian Storey mengatakan, tindakan represif tersebut menyebabkan masyarakat Melayu trauma, takut, dan benci terhadap pasukan keamanan Thailand. ${ }^{31}$

Pemerintah Thailand memperburuk kondisi dengan mengeluarkan kebijakan Dekrit Eksekutif Administrasi Publik dalam Situasi Darurat pada 19 Juli 2005 di Narathiwat, Pattani, dan Yala. Melalui dekrit tersebut, perdana menteri dapat mengeluarkan aturan untuk melarang warga selatan keluar rumah, menyebarkan berita, atau berpindah wilayah. ${ }^{32}$ Dekrit itu juga memberikan wewenang pihak keamanan untuk menangkap orang yang mencurigakan selama 7 hingga 30 hari tanpa proses pengadilan. ${ }^{33}$ Menurut International Crisis Group, aturan semacam itu hanya mengikis kepercayaan antara pemerintah Thailand dengan masyarakat Melayu Muslim. Sedangkan menurut Komisi Rekonsiliasi Nasional, dekrit tersebut tidak lain adalah 'lisensi untuk membunuh' bagi aparat keamanan Thailand. $^{34}$

\footnotetext{
${ }^{31}$ Storey, "Ethnic Separatism in Southern Thailand : Kingdom Fraying at the Edge?," 7.

${ }^{32}$ Pramudita, Fasisaka, and Kawatri, "Tindakan Pemerintah Thailand Dalam Merespons Gerakan Etnonasionalisme Di Thailand Selatan Tahun 20042006," 9.

${ }^{33}$ Storey, "Ethnic Separatism in Southern Thailand : Kingdom Fraying at the Edge?," 6.

${ }^{34}$ International Crisis Group, "Thailand's

Emergency Decree: No Solution," accessed

November 4, 2018,

https://www.crisisgroup.org/asia/south-eastasia/thailand/thailands-emergency-decree-nosolution.
}

Melihat situasi kritis yang terjadi di Thailand, OKI masuk sebagai pihak ketiga atau mediator. Tindakan OKI dilandaskan kepada komitmen untuk melindungi hakhak Muslim minoritas sesuai dengan prinsip dan mandat tersendiri. Piagam OKI menyatakan bahwa OKI mengamanatkan Sekretariat Jenderal untuk bekerjasama dengan organisasi internasional lainnya untuk menjamin hak-hak minoritas Muslim dan masyarakat negara non-anggota. Dalam misinya, OKI berkepentingan untuk menjaga kelompok minoritas dan komunitas muslim di negara non-anggota dan melakukan berbagai intervensi atas nama perlindungan hak asasi manusia yang berkonsentrasi pada agama sebagai elemen penting yang mengikat muslim secara bersama-sama. Hal ini membuat OKI, baik diminta atau tidak, cenderung menjadikan prinsipnya sebagai pijakan untuk mengatasi persoalan minoritas Muslim bahkan di negara non-anggota. ${ }^{35}$

Pendekatan yang dilakukan oleh OKI bersifat komunikatif dengan mengeluarkan rilisan pers serta membuka saluran dialog dengan pemerintah Thailand dan pihak pemberontak. Rilisan pers rutin dikeluarkan pada 2010, 2013, 2015, hingga 2016. Sedangkan dialog sudah dilakukan bahkan sejak 2005. Namun, persoalannya, dialog yang dilakukan oleh OKI bersifat terpisah. Sebagai mediator, OKI belum mampu mempertemukan pemerintah Thailand dan kelompok pemberontak dalam satu meja perundingan. Sedangkan dialog dengan pemerintah bermula ketika tahun 2005. Saat itu, Sekretaris Jenderal OKI Ekmelledin Ihsanoglu merilis beberapa siaran pers yang berisi kecaman terhadap aksi kekerasan serta himbauan untuk melaksanakan negosiasi dan dialog damai. OKI juga meminta pemerintah

\footnotetext{
${ }^{35}$ Waesahme, "The Organization of the Islamic Cooperation and the Conflict in Southern Thailand," 20.
} 
Yurisa Irawan, R. Widya Setiabudi Sumadinata, Windy Dermawan| Fragmentasi

Pemberontak Dan Durasi Perang Sipil: Thailand Selatan Pasca

Dimediasi Organisasi Kerjasama Islam

Thailand untuk memperlakukan warga Melayu Muslim sejajar dengan kelompok mayoritas. ${ }^{36}$ Kecamanan OKI ditanggapi dengan cepat oleh pemerintah Thailand lewat Menteri Luar Negeri Surakiart Sathirathai. Delegasi yang dipimpin oleh penasehat Sathirathai, Nissai Vejjajiva, dikirim ke markas besar OKI untuk menjelaskan situasi serta apa yang sudah dilakukan oleh pemerintah untuk menciptakan ketertiban. Sebagai negara pengamat, Thailand pun menyadari pentingnya peranan OKI dalam penyelesaian konflik serta mengundang organisasi tersebut untuk datang mengamati langsung kondisi Thailand. ${ }^{37}$

Dalam kunjungan ke Thailand, OKI membentuk tim pencari fakta dan menemukan bahwa pengabaian budaya dan agama masyarakat etnis Melayu Muslim adalah penyebab konflik. OKI menghimbau agar pemerintah berkomitmen bekerjasama untuk menemukan cara dan sarana pencegahan pelanggaran. ${ }^{38}$

Pada perkembangannya, dialog dengan pemerintah rupanya belum cukup. Meskipun OKI terus mengamati situasi Thailand, namun konflik masih berlangsung dan bahkan meningkat pada tahun 2007. Melihat kondisi seperti itu, OKI membuka saluran diplomasi dengan kelompok pemberontak Organisasi Pembebasan Bersatu Pattani (PULO) pada 2009. Setelah mendengar penjelasan dari Abu Yasir Fikri, pimpinan PULO saat itu, OKI menjanjikan bantuan dengan cara membicarakan persoalan dengan Thailand. Kemudian, OKI yang diwakili oleh Malaysia juga memfasilitasi pertemuan antara kelompok pemberontak Barisan

\footnotetext{
${ }^{36}$ Yusuf, "The Southern Thailand Conflictandthe Muslim World," 20.

${ }^{37}$ Organization of the Islamic Conference, OIC Secretary General Dispatches a Good-Offices Mission to Assess Conditions of the Muslims in Southern Thailand (Jeddah, 2005).

${ }^{38}$ Ibid.
}

Revolusi Nasional (BRN) dengan pemerintah Thailand di Kuala Lumpur pada 28 Februari 2013. ${ }^{39}$

Kendati OKI telah berupaya untuk melakukan proses bina damai, konflik terus berlanjut. Bahkan di waktu tertentu, skala kekerasan naik signifikan. Tercatat, sejak Januari 2004 hingga September 2018, konflik telah mencapai 6.871 korban tewas dan 13.460 korban luka. Angka ini menunjukkan bahwa konflik ini terus berlanjut meskipun ada upaya penyelesaian.

\section{Fragmentasi Pemberontak dan Stagnansi Konflik}

Fragmentasi

pemberontak sebetulnya memiliki akar pada bagaimana kelompok Pattani itu lahir tidak dengan satu visi sejak awal. Hal ini yang salah satunya menghalangi proses perundingan dengan pihak pemerintah. Perpecahaan itu dapat dilihat pada tiga hal. Pertama, kontestasi BRN dan PULO, dua kelompok pemberontak dominan yang berbeda visi, sehingga perundingan dengan BRN belum tentu memuaskan PULO, atau sebaliknya. Kedua, ketiadaan organisasi besar yang dapat menjembatani pemerintah Thailand dengan masyarakat Muslim Melayu sejak 200an. Ketiga, munculnya organisasi kecil dan sempalan dengan tujuan pragmatis yang terus meningkatkan eskalasi konflik.

Antara BRN dan PULO dapat dilihat perbedaan mencolok. Dari segi tujuan, BRN boleh dikatakan sedikit moderat dengan target sebatas menjadikan wilayah selatan sebagai daerah otonom, tetapi tetap dengan cara kekerasan. Sedangkan PULO yang muncul setelahnya, pada dekade 1970an, memiliki visi yang lebih radikal dengan melawan aparat pemerintah dengan

\footnotetext{
${ }^{39}$ Duncan McCargo, Southern Thailand: From Conflict to Negotiation? (Sydney: Lowy Institute, 2014), 8.
} 
aksi teror. ${ }^{40}$ PULO menargetkan kekerasan kepada warga sipil, ketimbang aparat negara.Sistem organisasi dan keanggotaan PULO bersifat tertutup dan rahasia, kader kepemimpinan tidak diketahui pasti dan tujuan tidak pernah dideklarasikan secara jelas. ${ }^{41} \mathrm{Hal}$ itu berbeda dengan BRN yang bergerak di bawah perpaduan gagasan sosialisme-komunisme dan Islam serta sering melaksanakan aksi militer bersama dengan gerilyawan Komunis Thai. $^{42}$ Tindakan yang diambil oleh BRN ini telah mengubah arah konflik yang melibatkan pemerintah Thailand dan minoritas Muslim Melayu menjadi sebuah konflik ideologi yang bisa melibatkan negara asing. Hubungan BRN dengan komunisme dipandang merugikan kelompok lain karena dapat menurunkan dukungan terhadap mereka dari solidaritas umat Muslim.

Namun, pemberontak Pattani bukan saja terbatas pada dua kelompok tersebut. Beberapa bahkan sulit diidentifikasi.Pemberontakan awal yang dapat dikenal adalah GAMPAR pada 1940an dengan tujuan murni pemisahan diri dari Thailand. Ketika pemberontakan ini belum mencapai tujuannya, yang lain, kelompok Haji Sulong muncul tidak dengan ideologi separatis, melainkan hanya menuntut pemerintah pusat agar lebih memperhatikan daerah selatan dengan kekhasan identitas keislamannya. ${ }^{43}$ Dua

\footnotetext{
${ }^{40}$ S.P. Harish, "Ethnic or Religious Cleavage? Investigating the Nature of the Conflict in Southern", Contemporary Southeast Asia, Vol. 28, No. 1 (April 2006), pp. 48-69 Published by: ISEAS - Yusof Ishak Institute, hal 57

${ }^{41}$ Marc Askew, "Insurgency and The Market for Violence in Southern Thailand," Journal Asian Survey 50, no. 6 (2010): 1114.

${ }^{42}$ Saiful Muzani, Pembangunan Dan Kebangkitan Islam Di Asia Tenggara (Jakarta: Pustaka LP3S, 1993), 178.

${ }^{43}$ Werner Kraus, "Islam In Thailand, Notes on the History of Muslim Provinces, Thai Islamic Modernism and the Separatist Movement in the
}

kelompok tersebut muncul dan tenggelam sebelum eranya BRN dan PULO.

Namun, ketika BRN dan PULO dapat dikatakan menjadi garda depan perlawanan Pattani terhadap Thailand, beberapa organisasi sempalan muncul seperti BRN-Koordinasi (BRN-C) dan New Pulo dengan metode teror yang lebih radikal. $^{44}$ Merekalah yang menaikan eskalasi konflik sebelum dapat diredam pada dekade 1990an. Menariknya, peredaman ini dapat diupayakan justru ketika dibentuknya wadah yang menjembatani pemerintah Thailand dengan masyarakat Melayu Muslim bernama Pusat Administrasi Provinsi Selatan Perbatasan (SBPAC). Namun, ketika organisasi ini dibubarkan pada awal 2000an, eskalasi kembali muncul yang ditandai dengan serangan bom bunuh diri dan teror. ${ }^{45}$ Peristiwa tahun 2004 adalah salah satu dampaknya.

Perpecahan pemberontak di selatan tidak hanya dapat digambarkan lewat hadirnya kelompok berlatar dan bertujuan beragam, tetapi juga lewat perilaku kelompok tersebut. Beberapa kelompok tidak memiliki kejelasan keanggotaan, pemimpin, dan bahkan tujuan sehingga sulit diambil tindakan pengamanan. Beberapa keanggotaan bersifat sangat rahasia atau melibatkan anak-anak yang keterlibatannya tidak diketahui oleh orang tua mereka. Selain itu, kelompok-kelompok ini juga tidak memperkenalkan dengan jelas siapa pimpinan kelompok mereka dan apa tujuan terbentuknya kelompok

South" Journal Institute of Muslim Affairs, 5:2, 410425, (1984), h. 413-414

${ }^{44}$ Lawrence E. Cline, "Thailand and the Insurgency in the South", Small Wars and Insurgencies, Vol 18, No. 2, 275-287 (2007), hal 279

${ }^{45}$ May Tan-Mullins, "Armed Conflict and

Resolutions in Southern Thailand”, Geographies of Peace and Armed Conflict Vol. 99, No. 5, (2009), pp. 922-931 Published by: Taylor \& Francis, Ltd., hal 926 
Yurisa Irawan, R. Widya Setiabudi Sumadinata, Windy Dermawan | Fragmentasi

Pemberontak Dan Durasi Perang Sipil: Thailand Selatan Pasca

Dimediasi Organisasi Kerjasama Islam

pemberontak tersebut. Mereka juga tidak mempublikasikan tuntutan yang jelas terhadap pemerintah. ${ }^{46}$

\section{Kesimpulan}

Konflik Thailand Selatan merupakan salah satu perang sipil dengan durasi panjang yang tengah berlangsung saat ini. Perang sipil di sini dimaknai sekadar konflik internal antara pemerintah dengan warga negaranya sendiri. Kendati demikian, konflik di Thailand Selatan, dalam fase konflik baru menanjak pada tahap kekerasan, dan belum mencapai tahap perang. Meskipun sebatas kekerasan, korban jiwa sudah mencapai ribuan orang sejak tahun 2004. Berbagai upaya resolusi konflik dilakukan termasuk ketika Organisasi Konferensi Islam (OKI) ikut campur sebagai pihak ketiga dalam upaya penyelesaian. OKI berhasil mencegah konflik kekerasan menjadi tambah parah sekaligus mencegah pecahnya perang terbuka antara kedua belah pihak. Namun, OKI tidak mampu menurunkan transformasi konflik dari fase kekerasan ke tahap di bawahnya, sehingga konflik terjebak dalam situasi kekerasan perang sipil yang mandek. Tulisan ini telah memaparkan bahwa hambatan penyelesaian tersebut bukan karena kurangnya kapabilitas OKI semata, melainkan karena adanya perpecahan di tubuh pemberontak sehingga sulit untuk mencapai kesepakatan. Fragmentasi kelompok pemberontak tersebut pada dasarnya dapat dilihat pada beberapa hal. Pertama, seberapa jauh kelompok yang satu dengan yang lain menjadikan Muslim Melayu sebagai identitas dalam pergerakan mereka. PULO memegang identitas ini dengan cukup konsisten, sehingga cenderung dapat dimediasi oleh OKI yang memang bergerak karena mandat sebagai pelindung hak-hak

\footnotetext{
${ }^{46}$ Askew, "Insurgency and The Market for Violence in Southern Thailand," 1113.
}

minoritas Muslim di negara non-anggota, tetapi kelompok lain, seperti BRN hadir dengan ideologi yang berbeda. Kedua, seberapa mampu pihak mediator merangkul pemberontak. OKI telah mengupayakan berbagai mediasi, tetapi hanya berhasil berdialog dengan PULO. Dengan BRN, OKI harus menggunakan peran anggotanya, Malaysia. Ketiga, hilangnya organisasi payung yang mewadahi masyarakat Melayu Muslim juga dapat mempertajam kemandekan perang sipil di Thailand. 
Yurisa Irawan, R. Widya Setiabudi Sumadinata, Windy Dermawan | Fragmentasi

Pemberontak Dan Durasi Perang Sipil: Thailand Selatan Pasca

Dimediasi Organisasi Kerjasama Islam

\section{DAFTAR PUSTAKA}

Askew, Marc. "Insurgency and The Market for Violence in Southern Thailand." Journal Asian Survey 50, no. 6 (2010): 1107-1134.

Baker, Chris, and Pasut Phongpaichi. A History of Thailand. Cambridge: Cambridge University Press, 2014.

Blattman, Christopher, and Miguel Edward. "Civil War." Journal of Economic Literature 48, no. 2 (2009): 3-57.

Castillo, Victor Luis Gutierrez. The Organization of Islamic Cooperation in Contemporary International Society, 2014.

Center for Systemic Peace. "Major Episodes of Political Violence 1946-2014." Accessed November 16, 2018. http://www.systemicpeace.org/warlist/warlist.htm\#.

Cline, Lawrence E. "Thailand and the Insurgency in the South", Small Wars and Insurgencies, Vol 18, No. 2, (2007), pp.275-287

Engvall, Anders, and Magnus Anderson. The Dynamics of Conflict in Southern Thailand, 2014.

Harish. S.P. "Ethnic or Religious Cleavage? Investigating the Nature of the Conflict in Southern". Contemporary Southeast Asia, Vol. 28, No. 1 (April 2006): pp. 48-69

Hashmat, Shahih Ahmad. The OIC Potential, Capabilities and Constraints for International Conflict Resolution. Islamabad, 2014.

International Crisis Group. Jihadism in Southern Thailand: A Phantom Menace. Brussels: International Crisis Group, 2017.

—. "Thailand's Emergency Decree: No Solution." Accessed November 4, 2018. https://www.crisisgroup.org/asia/south-east-asia/thailand/thailands-emergency-decreeno-solution.

Irawan, Yurisa. "Strategi Resolusi Konflik Organisasi Kerjasama Islam (OKI) Dalam Konflik Thailand Selatan." Universitas Andalas, 2016.

Kraus,Werner. "Islam In Thailand, Notes on the History of Muslim Provinces, Thai Islamic Modernism and the Separatist Movement in the South" Journal Institute of Muslim Affairs, 5:2, (1984), pp. 410-425

Liow, Joseph Chinyong. Muslim Resistance in Southern Thailand and Southern Philippines: Religion, Ideology and Politics. Washington D.C: The East-West Center Washington, 2006.

McCargo, Duncan. Southern Thailand: From Conflict to Negotiation? Sydney: Lowy Institute, 2014.

Muzani, Saiful. Pembangunan Dan Kebangkitan Islam Di Asia Tenggara. Jakarta: Pustaka LP3S, 1993.

Öberg, Magnus, and Kaare Strøm. Resources, Governance, and Civil Conflict. Oxon: Routledge, 2008.

Organization of the Islamic Conference. OIC Secretary General Dispatches a Good-Offices Mission to Assess Conditions of the Muslims in Southern Thailand. Jeddah, 2005.

Pew Templation. "Global Religious Futures." Accessed November 4, 2018. http://www.globalreligiousfutures.org/countries.

Pramudita, Gede Richard, Idin Fasisaka, and Putu Titah Kawatri. "Tindakan Pemerintah Thailand Dalam Merespons Gerakan Etnonasionalisme Di Thailand Selatan Tahun 2004-2006." Universitas Udayana, 2015. 
Yurisa Irawan, R. Widya Setiabudi Sumadinata, Windy Dermawan| Fragmentasi

Pemberontak Dan Durasi Perang Sipil: Thailand Selatan Pasca

Dimediasi Organisasi Kerjasama Islam

Ramsbotham, Oliver, Tom Woodhouse, and Hugh Miall. Contemporary Conflict Resolution: The Prevention, Management and Transformation of Deadly Conflicts. Cambridge: Polity Press, 2011.

Rupprecht, Kathrine. "Separatist Conflicts in the ASEAN Region: Comparing Southern Thailand and Mindanao." Austrian Journal of South-East Asian Studies 1, no. 7 (2014): 21-40.

Sarosi, Diana, and Janjira Sombatpoonsiri. "Arming Civilians for Self-Defense : The Impact of Firearm Proliferation on the Conflict Dynamics in Southern Thailand." Global Change, Peace \& Security 23, no. 3 (2011): 387-403.

Sharqieh, Ibrahim. "Can the Organization of Islamic Cooperation (OIC) Resolve Conflict?" Peace and Conflict Studies 19, no. 2 (2012): 162-179.

Storey, Ian. "Ethnic Separatism in Southern Thailand : Kingdom Fraying at the Edge?" AsiaPacific Center for Security Studies 35, no. 1 (2007): 31-51.

Tan-Mullins, May. "Armed Conflict and Resolutions in Southern Thailand", Geographies of Peace and Armed Conflict Vol. 99, No. 5, (2009), pp. 922-931

Thnapramsing, Patcharawat. "Solving the Conflict in Southern Thailand." Strategy Research Project (2009).

Waesahme, Paoyee. "The Organization of the Islamic Cooperation and the Conflict in Southern Thailand.” Victoria University of Wellington, 2012.

Walter, Barbara F. "Civil Wars, Conflict Resolution, and Bargaining Theory." In Handbook of International Relations, 656-672. 2nd ed. London: Sage Publication, 2013.

Yusuf, Imtiyaz. "The Southern Thailand Conflictandthe Muslim World." Journal of Muslim Minority Affairs 2, no. 27 (2007): 319-339. 